\title{
Educação Ambiental Integradora (EAI): Unindo saberes em prol da consciência ambiental sobre a problemática do lixo
}

Eduardo Beltrão de Lucena Córdula ${ }^{1}$

\begin{abstract}
RESUMO: A escola pública necessita atuar intensamente para formação da consciência dos seus alunos, pois o ensino formal por si próprio não consegue abarcar esta responsabilidade e, para auxiliar neste processo temos a educação ambiental que traz resultados a curto, médio e longo prazo, através de mudanças nos hábitos comportamentais dos alunos do $6^{\circ}$ ao $9^{\circ}$ ano do Ensino Fundamental II que, sensibilizados através de uma práxis numa ótica lúdica, passam para uma cultura de conservação consciente quanto aos problemas ambientais, principalmente, no tocante ao lixo doméstico.
\end{abstract}

Palavras-chave: educação ambiental; escola pública; lixo.

\section{INTRODUÇÃO}

Educação Ambiental (EA) antes de tudo é trabalhar em prol da qualidade de vida e da sustentabilidade para estas e as futuras gerações, através da diagnose de problemas que afetam o meio ambiente pelas inúmeras ações antrópicas que o modificam e que estão vinculadas diretamente a uma falta de consciência, respeito e do pleno exercício da cidadania na sociedade humana. Porém, tal advento de inconsciência persiste ao longo das décadas, desde a formação da polis e que acelerou com a revolução industrial. Para mudarmos este quadro, se faz necessário a incorporação de uma cultura de preservação individual e coletiva pela nossa sociedade (DIAS, 1998).

\begin{abstract}
"A raiz desta crise está na maneira que o homem conhece e transforma a sua realidade, produto de uma ética funcional ou utilitarista, que não permite a reflexão das conseqüências dos atos humanos, ma que foi e continua sendo motivadora de uma progressiva desvalorização dos processos integrados em prol de uma gritante racionalização decompositora de todos os processos subjetivos, sociais e naturais". (CHADDAD, 2010)
\end{abstract}

Neste sentido, apenas ações não determinam as mudanças de atitudes e a incorporação de um comportamento ambientalmente responsável, pois são pontuais e buscam imediatismos a pequenas frações do prisma global em que estamos imersos. Portanto, uma metodologia que estimule cognitivamente as comunidades e traga verdadeiramente uma aprendizagem ambiental, para então, podermos ter mudanças de valores e com reflexos em nosso meio ambiente (TANNER, 1978).

\footnotetext{
"Todos têm direito ao meio ambiente ecologicamente equilibrado, bem de uso comum do povo e essencial à sadia qualidade de vida, impondo-se ao poder público e à coletividade o dever de defendê-lo e preservá-lo para as presentes e futuras gerações". (BRASIL, 1988, p. 40).
} 
Dentro das disciplinas do ensino regular das escolas públicas, a EA ainda não faz parte do currículo formal, sendo trabalhada na forma de projetos pedagógicos (disciplinar ou interdisciplinar), mas com direcionamento apenas como um referencial de trabalhos com conceitos ligados as ciências naturais ( BRANCO, 2003). Enquanto que conceitos mais amplos e interconexões que são altamente necessárias para gênese na mudança comportamental, não são realizadas por motivos diversos, indo do despreparo a uma carência de uma visão holística, que precisa fundamentada em uma filosofia de vida, e não apenas em mais um projeto acadêmico ou escolar, pois estamos lidando com vidas e com o nosso futuro neste planeta (LOVELOCK, 2006).

"A educação ambiental é um componente essencial e permanente da educação nacional, devendo estar presente, de forma articulada, em todos os níveis e modalidades do processo educativo, em caráter formal e não-formal". (BRASÍLIA, 1999, p. 01).

"A educação ambiental estudada nas escolas, até pouco tempo atrás, aparecia como figurante de algumas disciplinas, tais como Ciências (no antigo primeiro grau) e Biologia (no antigo segundo grau). Tinha, até então, um caráter meramente informativo e, mais do que isso, passar a ter um caráter formativo; formando hábitos, atitudes e comportamentos, capazes de sustentar o Homem acima da natureza, tampouco subjugá-lo a ela; a idéia é de harmonia, com vistas à preservação de ambos". (BRANCO, 2003, p. 03).

Quando nosso olhar se volta à disciplina de ciências do Ensino Fundamental II, no foco de pesquisa, que por conteúdos curriculares possui mais afinidade com a EA, pois o currículo formal contempla temas e informações ligados a educação ambiental, mas não como trabalhar com os alunos de forma a fugir da pedagogia clássica, e que muitas vezes, são tratados apenas teoricamente nas escolas públicas, por inúmeras carências, e desconectados da prática, reduzem o aprendizado e impossibilitam as conexões necessárias para gerar a consciência ambiental. Neste sentido, projetos desenvolvidos com bagagem metodológica de diagnose, aplicação de ações e avaliação (método empírico), são de suma importância para enriquecimento e valorização tanto do ensino como da escola, e também, para trazermos uma mudança de atitudes perante nossos alunos e para sua plena formação na sociedade contemporânea (BRASÍLIA, 1999).

"A Educação Ambiental é fundamentalmente uma educação para a resolução de problemas, a partir das bases filosóficas do holismo, da sustentabilidade e do aprimoramento". (SÃO PAULO, 1999, p. 17).

Para que tenhamos um trabalho com resultados, proporcionais a realidade vivenciada, precisamos escolher um tema foco que interligue vários outros conhecimentos e que esteja diretamente relacionados à problemática ambiental gritante que é o aquecimento global (AG). Nesta rede viva de conexões, que mantém o equilíbrio global (CAPRA, 2006) e que está em declínio acelerado, temos o problema secular do resíduo solido doméstico que é o maior problema enfrentado nos centros urbanos (CÓRDULA, 1999), que provoca poluição dos ambientes e favorece o AG. Na escola, para a disciplina de ciências, este conteúdo faz conexões dietas com conteúdos e com a realidade local, além de trabalhá-lo no paradigma do "agir local e pensar global", preconizado por DIAS (1998). Tal resíduo é constatado pelo acúmulo e deposição inadequados pelas ruas, vielas, praças, etc., devido simplesmente, a carência de hábitos conscientes da polução sobre este poluente (SIBRÃO, 1999), que persistem ao longo do tempo desde o início da civilização à sociedade contemporânea (CÓRDULA et al., 1999). 


\section{DESENVOLVIMENTO}

I - Local

O município de Cabedelo está localizado no litoral Norte do Estado da Paraíba, sendo uma península, por possuir limites ao sul com o município de João Pessoa, a leste com o oceano Atlântico, a oeste com o rio Paraíba.

Possui ainda como ambientais naturais: uma vasta extensão de praias (Intermares, Poço, Camboinha I, II e III, Areia Dourada, Praia Formosa, Areial e Praia do Forte), restingas, dunas, manguezais e resquícios de Mata Atlântica (Mata do Amém e Mata do Estado) formando duas ilhas verdes (CÓRDULA, 2009a).

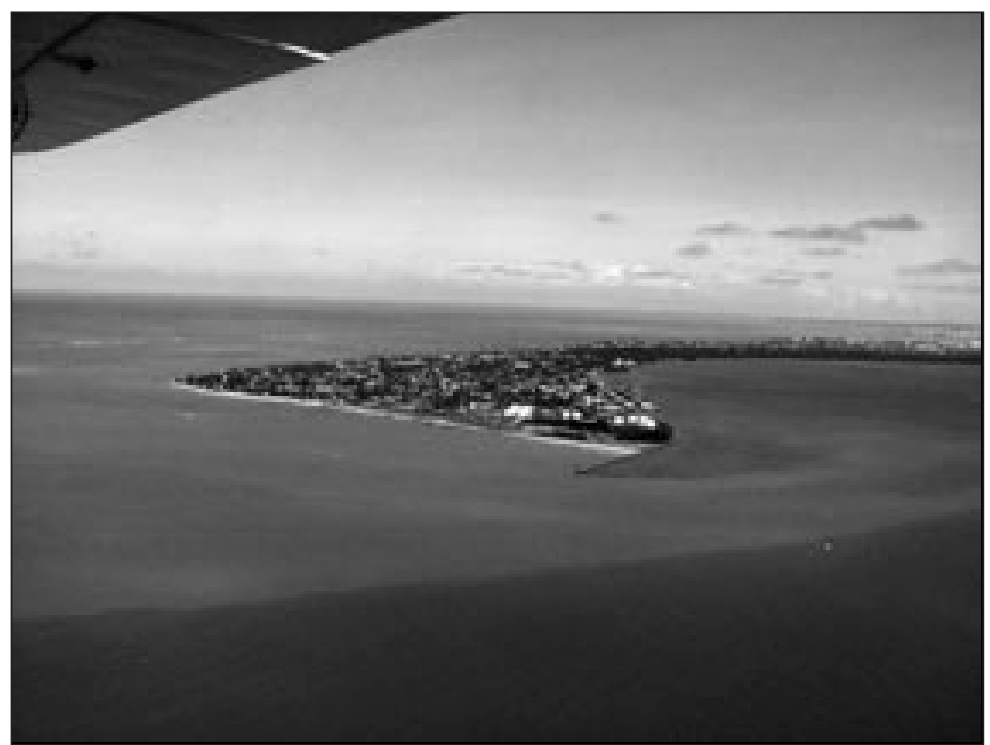

Figura 1 - Município de Cabedelo, visão aérea.

(Fonte: Secretaria Municipal de Pesca e Meio Ambiente)

\section{II - A Problemática}

Imerso nesta imensidão de áreas naturais, temos problemas ambientais das diversas ordens, alguns com maior intensidade como o caso do lixo depositado em áreas inadequados ou mal acondicionado, o que acaba se espalhando pelas ruas e terrenos dos bairros (CÓRDULA, 2009).

\section{III - Metodologia}

Para diagnosticarmos a problemática em questão, realizamos uma ecopercepção (DIAS, 2004) do ambiente urbano e dos hábitos da população todos os dias ao longo do ano letivo escolar, principalmente no entorno da escola, além da diagnose da problemática na própria escola com uma "observação participante e uma análise documental" (SILVA, 1990, p. 27).

A escola em questão é a pública municipal Major Adolfo Pereira Maia, possui turmas do $6^{\circ}$ ao $9^{\circ}$ ano do Ensino Fundamental II, nos turnos da manhã e tarde, estando localizada no centro da cidade e atende alunos pertencentes a famílias com baixa renda, oriundos de comunidades circunvizinhas carentes de condições sociais e fito-sanitárias.

Para sensibilização dos alunos ao longo do ano letivo, trabalhamos conteúdos teóricos numa ótica lúdica ( aprendizado-recreativo ), e após extensa pesquisa bibliográfica (análise documental), conciliamos a pedagogia convencional com os teóricos: Jean Piaget [cognitivista] (PIAGET, 1977), Howard Gardner [inteligências múltiplas] (TRAVASSOS, 
2001), Lev Vygotsky [histórico-social] (ZACHARIAS, 2009b), Paulo Freire [sócio-cultural] (MIZUKAMI, 1986) e Emília Ferreiro [construtivista]) (ZACHARIAS, 2009a), a ecopedagogia preconizada por Moacir Gadotti (GADOTTI, 2009), e da própria Educação Ambiental com Genebaldo Freire Dias (DIAS, 1998).

Os conceitos da literatura específica embasaram as atividades lúdicas, o que mostrou grandes resultados nas vidas destas crianças, pois passaram a se perceberem dentro do município como cidadãos que podem atuar para mudar os problemas ambientais, principalmente, no caso do lixo, de forma disciplinar e utilizando as bases da transversalidade: meio ambiente (lixo, 4R's, poluição, biodiversidade, recursos naturais não-renováveis e renováveis, biosfera, ecossistemas e biomas) (BRASIL, 1998).

\section{IV - Procedimentos (Ações)}

As ações foram desenvolvidas aos sábados ou em horário oposto ao turno normal das aulas dos alunos. Os conteúdos eram organizados e planejados de acordo com a faixa etária, a série em curso e a problemática em foco, diagnosticada na comunidade (o lixo). Quando necessário, as atividades aconteciam no horário das aulas da disciplina de ciências.

Todo o trabalho foi desenvolvido ao longo dos anos letivos de Desde 2005 a 2008, e em 2009 foi realizada a análise de todo o material obtido e os resultados alcançados.

Durante este período de contínua transformação da aplicação dos conteúdos, houve dois momentos de reflexão/decisão para a continuidade e desenvolvimento das atividades: em 2006 e 2008, para planejamento das atividades para o ano seguinte. Porém, a atuação com os alunos não ficaram estagnadas, mas sim, realizamos atividades de manutenção com as turmas.

Durante este longo período de atuação, constatamos que oito técnicas e se destacaram e mantivemos sua contínua utilização, só modificando a abordagem perante as turmas:

1 - Leitura de Textos: com temas ligados a preservação, ao meio ambiente, aos 3R's e ao nosso papel na melhoria da qualidade de vida (DIAS, 1998). Procedíamos com a escolha dos temas para os bimestres do ano letivo e procedíamos com leitura individual e pessoal, ou com leitura compartilhada e ainda em grupos, na temática dos PCN's (BRASIL, 1998). Em seguida, interpretação textual, com produção de novos textos pelos alunos ou com produção de: fichamentos, resumos e relatórios;

2 - Exibição de Vídeos Educativos: documentários pré-selecionados para exibição de acordo com a faixa etária e o nível de compreensão, com posterior círculo de debates e elaboração de sinopses (POLITO, 1997). Os DVDs foram selecionados com base no tempo de exibição e o conteúdo de acordo com a série e o programa curricular, para não desvirtuar dos conteúdos ministrados em sala de aula. A temática abordada foi dos ecossistemas, lixo e do aquecimento global.

3 - Círculo de Debates: na escola em exercício democrático e de plena consciência sobre a problemática do lixo, com participação de todos os alunos da escola, através de prós e contras, com jogo de perguntas e respostas, criávamos um ambiente propício à construção do conhecimento. Posteriormente, montávamos grupos, encarregados de defender o lixo, de acusá-lo dos problemas e de encontra soluções, numa ótica que envolvesse na discussão a comunidade, a sociedade, a deposição e o destino do resíduo. Ao final na culminância, os professores pediam a elaboração de relatórios do evento, com as devidas conclusões pessoais (LIBÂNEO, 1994) (Figura 2);

4 - Pelotão Ambiental: participação do Desfile Cívico de 7 de Setembro com os alunos de todas as séries da escola, representando o engajamento e sensibilização aos problemas ambientais (Figura 3 ); 
5 - Produção de Material Educativo: em oficinas artísticas com manufatura de cartazes, painéis, cartilhas, textos de própria autoria, folders, que são utilizados na escola em campanhas ou outras atividades (BRANCO, 1998), a partir dos conhecimentos adquiridos;

6 - Elaboração de Trabalhos: que estimulam a sensibilização e que foram expostos e apresentados em mostras culturais na escola, sempre no segundo semestre, onde a comunidade do seu entorno se torna visitante e ouvinte das apresentações (GADOTTI, 2009), com produção de: álbuns seriados, maquetes, reprodução de ambientes, murais, painéis e mostra de objetos (Figura 4);

7 - Oficinas Lúdicas: com dinâmicas que estimulam a cooperação união, respeito, o conhecimento próprio de cada aluno, a socialização e conduzidas pelo facilitador, promove a gênese do aprendizado na área ambiental e promove o crescimento intelectual do alunado, gerando a sensibilização necessária para torná-los aptos a multiplicarem os conhecimentos adquiridos em seus bairros de origem (ANDREOLA, 1998) (Figura 5);

8 - Ecopercepção na Comunidade do Entorno: passeios excursionamos na comunidade do entorno da escola, para observação da problemática ambiental do lixo depositado inadequadamente, nos terrenos e nas ruas, seus efeitos poluidores (DIAS, 2004; LIBÂNEO, 1994) (Figura 6);

9 - Realização de Palestra e Apresentação Teatral: com convidados de órgãos públicos e entidades não-governamentais, para abordar temas de relevante interesse da comunidade e que tratem da temática ambiental (Figura 7).

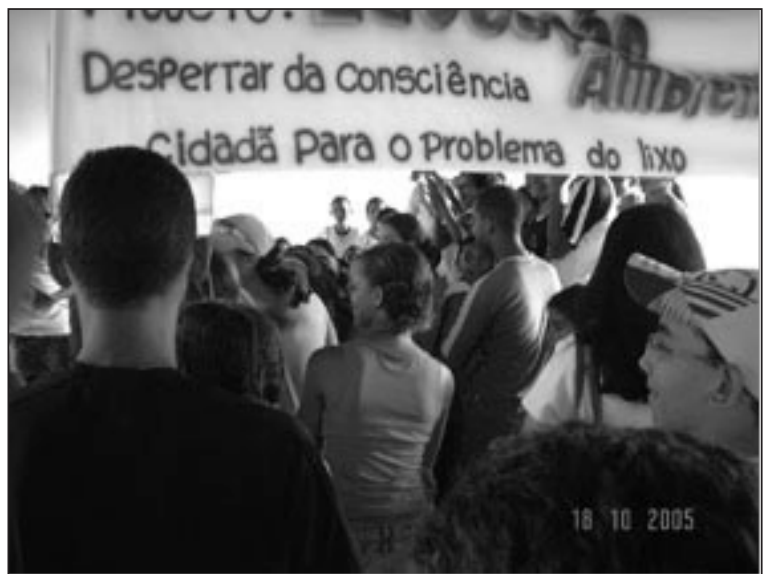

Figura 2 - Debates na escola (2005)

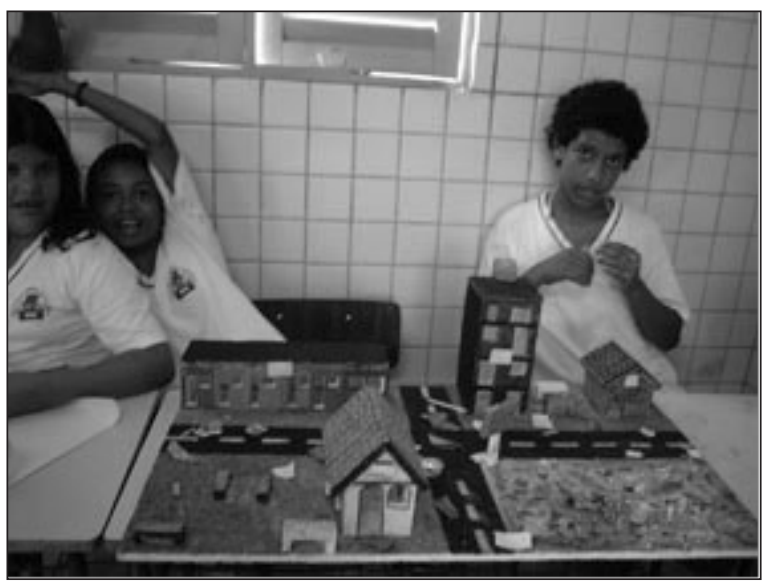

Figura 4 - Trabalhos Elaborados (2005)

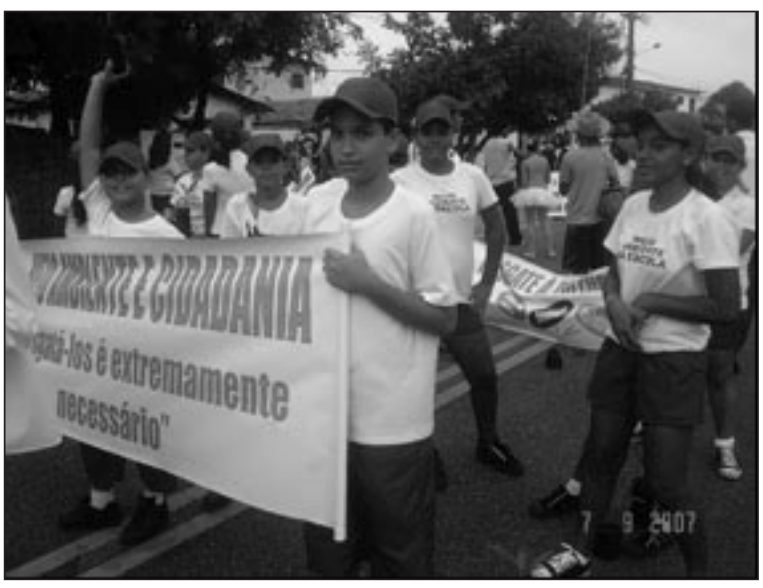

Figura 3 - Pelotão ambiental (2007)

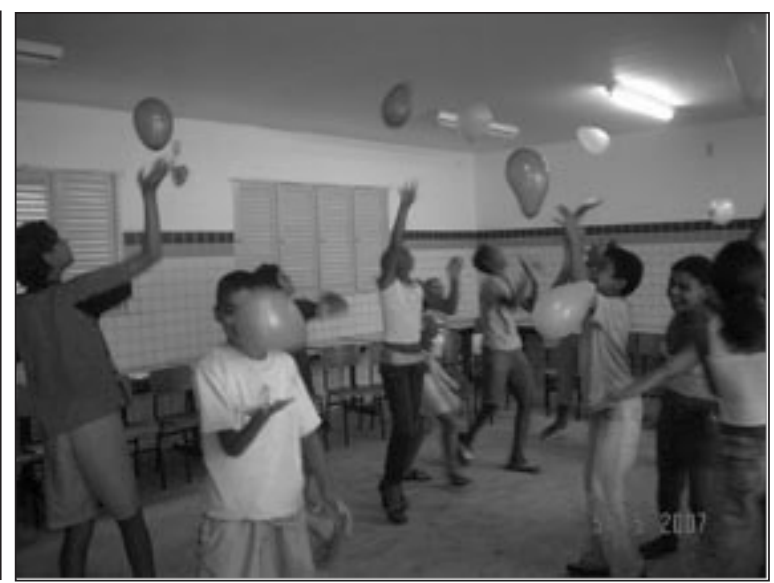

Figura 5 - Oficina Lúdica (2007) 


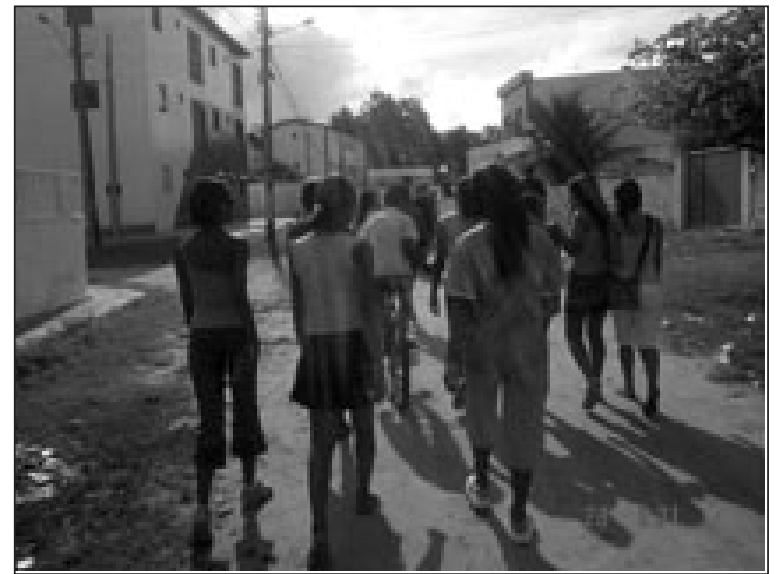

Figura 6 - Ecopercepção dos alunos (2005)

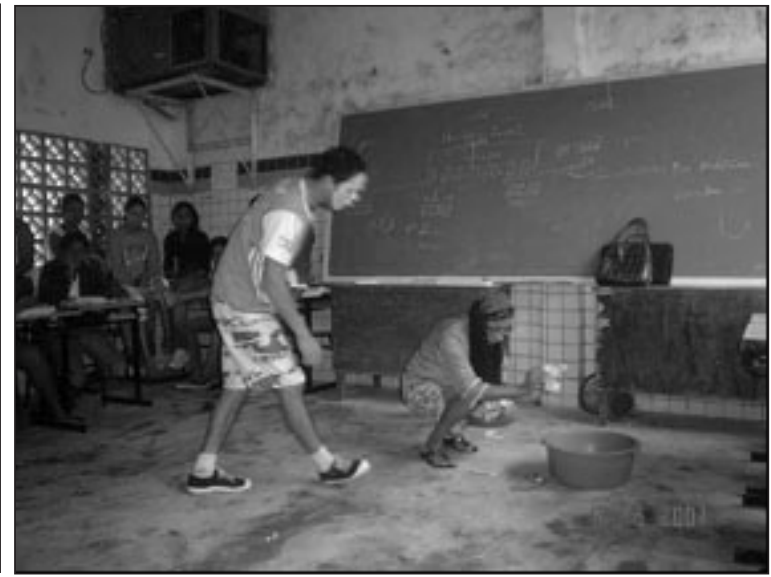

Figura 7 - Apresentação Teatral (2005)

\section{V - Resultados Alcançados}

Ao iniciar o trabalho de sensibilização dos alunos de forma disciplinar, constatamos dois problemas: primeiro, ter uma metodologia de trabalho adequada para promover a Educação Ambiental e, em segundo, trazer atividades atrativas aos alunos que, ao mesmo tempo, estimulasse o processo educativo desejado e trouxesse à tona a consciência como foco multiplicador em seus lares, verificados pelos relatos dos pais dos alunos, bem como, na própria escola, cuja estrutura física que era constantemente degradada com pichações e danos do material logístico, passaram a serem conservados, com sensível redução do lixo que se acumulava no chão das salas e corredores, sendo um problema sanitário e estético ao ambiente em questão.

Com base na bibliografia específica, tomando como princípio a ecopedagogia e adaptando outros métodos e técnicas de ensino convencionais, conseguimos tornar atrativas as atividades planejadas, que passaram de simples conteúdos de ensino, para construções educativas: teoria e prática (práxis) (CÓRDULA, 1999), em uma ótica lúdica. Com isto, foram trabalhados o lado social, o físico, o emocional e o cognitivo dos alunos do Ensino Fundamental II.

Os alunos passaram a ter maior interesse pelos conteúdos curriculares e a possuir maior senso de cidadania e responsabilidade perante o ambiente em que estão inseridos e com relação ao meio ambiente, manifestos nas atividades curriculares desenvolvidas em sala de aula na disciplina de ciências.

\section{CONCLUSÃO}

Graças ao apoio da gestão e supervisão escolar, de entidades e órgãos públicos que colaboraram com as atividades do projeto, através de palestras e apresentações teatrais, conseguimos ter um reforço positivo na sensibilização dos alunos com aplicação da Educação Ambiental e que retornaram (feedback) nas oficinas e demais atividades.

A escola passou a ter uma maior conservação do seu patrimônio físico, os alunos segundo relato dos próprios professores se engajaram mais nas atividades curriculares da escola.

\section{Agradecimentos}

A todos que fazem a Escola Municipal Major Adolfo Pereira Maia.

Secretaria Municipal de Educação e Cultura de Cabedelo - PB.

Secretaria Municipal de Pesca e Meio Ambiente de Cabedelo - PB

Aos alunos e seus responsáveis pela participação e engajamento. 


\section{REFERÊNCIAS}

ANDREOLA, B. A. Dinâmica de Grupo: jogo da vida e didática do futuro. 15. ed. Rio de Janeiro: Vozes, 1998.

BRANCO, S. Educação Ambiental: metodologia e prática de ensino. 2003.

BRASIL. Constituição Federal. Brasília: Senado Federal, 1988. Disponível em: <http:// www.senado.gov.br/sf/legislacao/const/con1988/CON1988_30.06.2004/CON1988.pdf>. Acesso em: 09 mai. 2009.

BRASIL. Ministério da Educação. Parâmetros Curriculares Nacionais - terceiro e quarto ciclos: apresentação dos temas transversais. Brasília: MEC/SEF, 1998.

IBAMA. Educação para um Futuro Sustentável: uma visão para ações compartilhadas/ UNESCO. Brasília: IBAMA, 1999.

CAPRA, F. A Teia da Vida: uma nova compreensão científica dos sistemas vivos. Tradução Newton Roberval Eichemberg. São Paulo: Cultrix, 2006. 256p.

CÓRDULA, E. B. L. Realidade e Criatividade no Contexto Educacional. In: GUERRA, R. A. T. [Org.]. Educação Ambiental: textos de apoio. João Pessoa: Editora Universitária da UFPB, 1999. p. 56-57.

CÓRDULA, E. B. L.; KENNEDY, A. S. \& GUERRA, R. T. Poluição Eca! In: GUERRA, R. A. T. [Org.]. Educação Ambiental: textos de apoio. João Pessoa: Editora Universitária da UFPB, 1999. p. 76-80.

CÓRDULA, E. B. L.; GUERRA, R. T. ...Nossas Ruas?. In: GUERRA, R. A. T. [Org.]. Educação Ambiental: textos de apoio. João Pessoa: Editora Universitária da UFPB, 1999. p. 106-107.

CÓRDULA, E. B. L.; FONSÊCA, P. N. Educação Socioambiental em quatro temas para alunos do ensino fundamental: cidadania, sexualidade, drogas e meio ambiente. In: CONGRESSO NACIONAL DE EDUCAÇÃO AMBIENTAL / ENCONTRO NORDESTINO DE BIOGEOGRAFIA, 1,3, 2009, João Pessoa. Anais... João Pessoa: Ed. Universitária de UFPB, 2009. p. 725-733, v. 3, CD-ROM.

CÓRDULA, E. B. L. \& FONSÊCA, P. N. Desenvolvendo Atitudes Pró-Ambientais em Alunos do $6^{\circ}$ Ano em uma Escola Pública. In: I CONGRESSO NACIONAL DE EUCAÇÃO AMBIENTAL / ENCONTRO NORDESTINO DE BIOGEOGRAFIA, 1,3, 2009, João Pessoa.. Anais... João Pessoa: Ed. Universitária de UFPB, 2009b.p. 650-656, v. 3. CD-ROM.

DIAS, G. F. Educação Ambiental: Princípios e Práticas. 5. ed. São Paulo: Gaia, 1998. Gaia, 2004.

Ecopercepção: um resumo didático dos desafios socioambientais. São Paulo:

GADOTTI, M. A Ecopedagogia como pedagogia apropriada ao processo da Carta da Terra. Fórum Nacional de Pedagogia - UFMT, 2000. Disponível em: <http://www.ufmt.br/ revista/arquivo/rev21/moacir_gadotti.htm>. Acesso em: 21 mar. 2009.

LIBÂNEO, J. C. Didática. São Paulo: Cortez, 1994. 261p.

LOVELOCK, J. A Vingança de Gaia. Tradução Ivo Korytowski. Rio de Janeiro: Intrínseca. 2006. 160p.

MIZUKAMI, M. G. N. Ensino: as abordagens do processo. São Paulo: EPU, 1986.

POLITO, R. Recursos Audiovisuais: nas apresentações de sucesso. 3. ed. São Paulo: Saraiva, 1997. 
PIAGET, J. O desenvolvimento do pensamento. Equilíbrio das estruturas cognitivas. Lisboa: Dom Quixote, 1977.

SÃO PAULO (Estado). Conceitos para se Fazer Educação Ambiental. 3. ed. São Paulo: Secretaria do Meio Ambiente/CEA,1999. 115p. (Série Educação Ambiental)

SIBRÃO, E. A. R. Onde Jogo Meu Lixo. In: GUERRA, R. A. T. [Org.]. Educação Ambiental: textos de apoio. João Pessoa: Editora Universitária da UFPB, 199. p. 60-61.

SILVA, T. M. N. A Construção do Currículo na Sala de Aula: o professor como pesquisador. São Paulo: EPU, 1990. 74p. (Temas Básico de Educação)

TANNER, R. T. Educação Ambiental. São Paulo: Summus/EDUSP, 1978.

TRAVASSOS, L. C. P. Inteligências Múltiplas. In: Revista de Biologia e Ciências da Terra, vol. 1, n.2, 2001. Disponível em: <http://eduep.uepb.edu.br/rbct/sumarios/pdf/inteligencias multiplas.pdf>. Acesso em: 08 jan. 2010.

ZACHARIAS, V. L. C. Emília Ferreiro. Disponível em <http://www.centrorefeducacional. com.br/contribui.html>. Acesso em: 23 fev. 2009.

Lev S. Vygotsky. Disponível em <http://www.centrorefeducacional.com.br/ vygotsky.html>. Acesso em: 23 fev. 2009.

1 Especialista em Supervisão Escolar - IESP (2009), Licenciado em Biologia - UFPB (2002), Professor da Educação Básica da Prefeitura Municipal de Cabedelo - PB, Educador Sócio-Ambiental. Contato: Caixa Postal 147 - Intermares. Cep: 58.310-971. Cabedelo - PB. e-mail: <ecordula@ hotmail.com>. 